\title{
Real-time detection of Chemical Warfare Agents at clearance decontamination levels for surface contamination: a challenge for civilian authorities
}

\author{
Dieter Rothbacher ${ }^{\mathrm{a}}{ }_{\mathbb{D}}$ \\ CBRN Protection GmbH, Vienna, Austria
}

Received: 9 January 2021 / Accepted: 23 March 2021

(C) The Author(s) 2021

\begin{abstract}
NATO doctrine considers clearance decontamination to be applicable after the termination of a CBRN incident and largely deems the conduct of clearance decontamination to be a civilian, not a military, capability (NATO Standard NATO STANREC 4784 CBRN Clearance Decontamination, Study Draft 1, November 2015). Clearance decontamination procedures are such that the process is verified as being achieved by determining the residual contamination levels on every part of various surfaces of equipment and infrastructure, and by demonstrating that such levels are below the ones that are pre-determined by the relevant civilian authorities, who are responsible for the safety of the civilian population (NATO Standard NATO STANREC 4784 CBRN Clearance Decontamination, Study Draft 1, November 2015). The current desirable surface contamination detection levels for some Chemical Warfare Agents are technically challenging and may be beyond the capabilities of current technologies of military and civilian authorities. Can those low levels be detected, in real time, with existing technologies? Proton Transfer Reaction-Time of Flight-Mass Spectrometry (PTR-ToF-MS) enables simultaneous real-time detection, monitoring, and quantification of volatile organic compounds. Trials and evaluations with this PTR-ToF-MS technology, using Chemical Warfare Agents as contaminants, will show that this technology is an invaluable asset in supporting civilian authorities when determining safe levels of surface contamination in real time, after the completion of decontamination operations.
\end{abstract}

\section{Introduction}

This paper focuses on the remediation phase of a CBRNe incident, which includes decontamination measures. This last phase of an incident is - in my view-a "stepchild" of the CBRNe industry, as it includes very long and technically challenging processes, such as the process of declaring an incident site safe. An incident site could be deemed "clean" when it "is no longer a hazard for the user". However, this definition is not accurate, because the expression "hazard for the user" is on a sliding scale. This paper shall investigate what is considered as being safe.

Clearance decontamination supported by PTR-ToF-MS (Proton Transfer Reaction-Time of Flight-Mass Spectrometry) trace detection technology: a way forward.

a e-mail: dieter.rothbacher@cbrn-protection.com (corresponding author) 
The problems and the very time-consuming operations to render a site safe became very obvious - and also known to the general public-during the cleaning operations after the recent (2018) incidents in the UK, which involved a deadly substance-namely Novichok-a nerve agent belonging to the group of Chemical Warfare Agents (CWA).

The decontamination (or cleaning) of an affected site involves a process of testing, removal of items and materials that may have been contaminated, but also chemical cleaning and retesting. Testing and retesting are very time-consuming operations, as they involve the analysis of the samples taken, which is usually performed in (accredited) chemical laboratories. Can this process be shortened? This is another question that this paper tries to answer.

The conceptual approach of this paper is based upon a question that I have been faced with many times, in operational settings as well as in training environments: How can safe levels of surface contamination be established in a fast, real-time, and analytically recognized manner? In 2017, when I started working with the Proton Transfer Reaction Time of Flight Mass Spectrometry (PTR-ToF-MS) technology, I realized that instruments based upon this technology could finally allow the relevant actors to overcome the existing limitations and make them able to determine safe, residual contamination levels in a fast and reliable manner. I have engaged in a technical cooperation with an Austrian company, IONICON Analytik $\mathrm{GmbH}$, that has developed that technology for industrial applications.

In August 2018, for the first time ever with that technology, we carried out field trials with Chemical Warfare Agents in a specialized laboratory in the Czech Republic. Such trials aimed at clarifying whether clearance decontamination could be supported by PTR-ToF-MS technology.

\section{Chemical Warfare Agents}

Chemical Warfare Agents-often referred to as Chemical Weapons-are chemicals used to cause intentional death or harm through their toxic properties; as such, they are defined in the Chemical Weapons Convention [1].

$\mathrm{CW}$ agents used in warfare are classified as follows [2]:

- Nerve agents

- Vesicants (blistering agents)

- Bloods agents (cyanogenic agents)

- Choking agents (pulmonary agents)

- Riot-control agents (tear gases)

- Psychomimetic agents

- Toxins.

It is important to note that NATO AEP-58 [3] recommends decontamination testing to be performed with two main types of CWAs: nerve and blister agents.

Therefore, this paper (and its laboratory trials) focuses on those two categories of Chemical Weapons.

\subsection{Residual contamination levels: field trials}

The question to be answered is: Are there are any residual contamination levels after a completed cycle with current decontamination technologies and procedures? This level of thorough decontamination should partially or totally remove all levels of contamination. But what are the amounts that the "residual contamination levels" expression refers to? The 
results of some thorough decontamination field trials, carried out in 2009 and in 2014, will shed light on this point.

The trials were carried out at a specialized facility that allows the outdoor use of Chemical Warfare Agents, using decontamination equipment that had been tested against current NATO standards (AEP-58). The product names of various decontamination solutions are not mentioned, and the test protocols (set up of the tests) are not explained in detail in this paper.

Two field tests were carried out by the author of this paper with one military unit in 2014 and with an international arms control organization (Organisation for the Prohibition of Chemical Weapons) in 2009.

The samples were contaminated with Chemical Warfare Agents; more specifically, they were calculated by the equivalent of $10 \mathrm{~g} / \mathrm{m}^{2}$. The surface areas of the contaminated painted metal plates were $5 \mathrm{~cm}$ by $5 \mathrm{~cm}$, for a total of $25 \mathrm{~cm}^{2}$.

Totally, 8 out of 24 samples showed no residual contamination (below LOD, Limit of Detection), according to the analytical laboratory results of the samples taken (wipe samples).

It can be concluded that two-thirds of the decontaminated surfaces were still contaminated with small amounts of Chemical Warfare Agents. Some of those residual amounts can be considered as traces, as decontamination efficiency was in the range of 90-100\%. Traces (or trace elements) of CWA are defined in a certain percentage of volume or weight, usually ranging from 0.1 to $0.01 \%$ [4], or as any element having an average concentration of less than about 100 parts per million atoms or less than $100 \mu \mathrm{g} / \mathrm{g}$ [5].

The wipe samples were analysed with GC-MS technology.

\section{How clean is safe? NATO desirable detection levels for surface contamination}

STANREC 4578 lists the essential and desirable surface contamination detection levels for some Chemical Warfare Agents. What are such desirable detection levels? They are defined as levels of detection - after completed decontamination - that will prevent exposure of individuals to have noticeable health effects; it is expected that detection equipment will detect contamination down to the levels shown in Table 1.

Below are the aforesaid levels_-divided into essential and desirable ones [6]:

According to NATO, it is clear that some of said levels are particularly challenging and may be beyond current detection technologies [6]. This paper demonstrates that there is a

Table 1 NATO desirable detection levels

\begin{tabular}{lllll}
\hline CWA & Surface & $\begin{array}{l}\text { Essential } \\
\text { level } \mathrm{g} / \mathrm{m}^{2}\end{array}$ & $\begin{array}{l}\text { Essential } \\
\text { level } \mu \mathrm{g} / \mathrm{cm}^{2}\end{array}$ & $\begin{array}{l}\text { Desirable } \\
\text { level } \mu \mathrm{g} / \mathrm{cm}^{2}\end{array}$ \\
\hline $\mathrm{G}$ & Material & 0.1 & 10 & 5.28 \\
$\mathrm{~V}$ & Material & 0.02 & 2 & 0.03 \\
$\mathrm{H}$ & Material & 0.1 & 10 & 1.5 \\
$\mathrm{GA}$ & Personnel & 0.0528 & 5.28 & 5.28 \\
$\mathrm{~GB}$ & Personnel & 0.0528 & 5.28 & 5.28 \\
$\mathrm{GD}$ & Personnel & 0.0111 & 1.11 & 1.11 \\
$\mathrm{GF}$ & Personnel & 0.0106 & 1.06 & 1.06 \\
$\mathrm{VX}$ & Personnel & 0.0003 & 0.03 & 0.03 \\
$\mathrm{HD}$ & Personnel & 0.0150 & 1.5 & 1.5 \\
\hline
\end{tabular}


technology (PTR-TOF-MS technology) that can detect surface contamination at those levels and therefore meet the desired NATO levels.

The detection and identification of CWA vapours, stemming from the surface contamination with low quantities, can also be considered as trace gas analysis.

\section{PTR-ToF-MS technology}

\subsection{Description}

Proton transfer reaction mass spectrometry (PTR-MS) is a technology that provides online monitoring of volatile organic compounds (VOCs). The main technical feature of this technology is that it offers a low detection threshold and a fast response time. PTR-MS commercial instruments are mainly based on the quadrupole analytical method. Their main limitation consists in the fact that they provide very little useful information, besides the nominal mass of ions detected. IONICON Analytik, instead, developed new instruments based on time-offlight (PTR-TOF-MS) analysers. This technology gives the user a higher mass resolution, which subsequently leads to more analytical data contained in the spectra.

PTR-ToF-MS technology can fill current gaps already identified by NATO in 2015; the trials conducted with CWA, as described in this paper, clearly demonstrated the capabilities of this technology.

\subsection{Hazard monitor}

The hazard monitor is a purpose-built IONICON PTR-TOF-MS, with up to $2000 \mathrm{cps} / \mathrm{ppbv}$ sensitivity and a 1-s detection limit of around $10 \mathrm{pptv}$, which is housed in two interconnected $19^{\prime \prime}$ cubic racks, with a total weight of about $90 \mathrm{~kg}$, for maximum flexibility.

Furthermore, the instrument is equipped with a sophisticated automated data processing software, which switches the ion chemistry and performs pattern matching algorithms according to substances entries in a database. This means that selectivity is considerably improved, i.e. the risk of false positives and negatives is reduced, and the user gets concentrations readings of the respective CWAs with a time resolution of down to $1 \mathrm{~s}$.

The trials with CWA allowed us to use-for the very first time- $-\mathrm{NH}_{4}{ }^{+}$reagent ions, which are produced without the need of any ammonia, in addition to $\mathrm{H}_{3} \mathrm{O}^{+}, \mathrm{NO}^{+}$and $\mathrm{O}_{2}{ }^{+}$, respectively.

\section{Trials description}

\subsection{Agents}

The agents used for the trials belong to two of the groups mentioned earlier in this paper:

Nerve agents and blister agents.

a. Nerve agents: tabun (GA); sarin (GB); soman (GD); cyclosarin (GF); VX

b. Blister agents: mustard (HD); nitrogen mustard (HN1); nitrogen mustard (HN3); Lewisite (L1).

What is important to note at this point is that the proton affinity for CWA can only be assessed after evaluation of the trials. The proton affinity for CWA - to my knowledge-is 
Table 2 Agent purity

\begin{tabular}{ll}
\hline Agent & Purity in $\%$ \\
\hline GA & 98.99 \\
GB & 99.74 \\
GD & 100 \\
GF & 95.29 \\
VX & 90.68 \\
HD & 100 \\
HN1 & 100 \\
HN3 & 100 \\
L1 & 70.98 \\
\hline
\end{tabular}

not recorded in any scientific literature, as tests with real CWA have not been done to the extent it was carried out for this project.

\subsubsection{Purity of agents}

The equipment used for our trials (PTR-ToF-MS) would pick up impurities of the abovementioned agents; it was therefore important to have the purity of agents assessed at the beginning.

The purities were as follows (Table 2):

Analytical reports of all agents used during the trials are referenced. Detailed information can be found in the relevant analytical reports [7].

\subsection{Primary ions}

Primary ions (also called reagent ions) are used for chemical ionization of the analytes. When $\mathrm{H}_{3} \mathrm{O}^{+}$is used as primary ions, the main ionization channel is proton transfer, i.e. the product ions are mainly protonated molecules $\left(\mathrm{M} \cdot \mathrm{H}^{+}\right)$. However, it should be noted that, although the energy transfer upon proton transfer is relatively small, in some cases fragmentation of the analyte molecules can occur.

In the IONICON PTR-ToF-MS technology, the primary ions can also be switched to $\mathrm{NH}_{4}{ }^{+}, \mathrm{O}_{2}{ }^{+}, \mathrm{NO}^{+}$and $\mathrm{Kr}^{+}$.

During our trials, we mainly used $\mathrm{H}_{3} \mathrm{O}^{+}$and $\mathrm{NH}_{4}{ }^{+}$.

\subsection{Solvents/dilution}

Two solvents were used for the dilution of Chemical Warfare Agents-Hexane and Dichloromethane.

- Hexane, a non-polar solvent, is commonly used in chromatography. Its chemical formula is $\mathrm{C}_{6} \mathrm{H}_{14}$, and it has a lower proton affinity than ammonia and water. Therefore, it does not get ionized via proton transfer from $\mathrm{NH}_{4}{ }^{+}$or $\mathrm{H}_{3} \mathrm{O}^{+}$and can be used as a solvent for chemical analytical trials where the dilution of the main component (in our case CWA) is required.

- The chemical formula of methylene dichloride (DCM, or methylene chloride, or dichloromethane) is $\mathrm{CH}_{2} \mathrm{Cl}_{2}$. It is widely used as a solvent and diluent. It also has a lower proton affinity than ammonia and water. 
Table 3 Steps of dilution

\begin{tabular}{lllllllll}
\hline Series & $\begin{array}{l}\text { Step 1 } \\
(\mu \mathrm{l})\end{array}$ & $\begin{array}{l}\text { Step 2 } \\
(\mathrm{mg})\end{array}$ & Step 3 & $\begin{array}{l}\text { Step 4 } \\
(\mathrm{ng})\end{array}$ & $\begin{array}{l}\text { Step 5 } \\
(\mathrm{ng})\end{array}$ & $\begin{array}{l}\text { Step 6 } \\
(\mathrm{ng})\end{array}$ & $\begin{array}{l}\text { Step 7 } \\
(\mathrm{ng})\end{array}$ & $\begin{array}{l}\text { Step 8 } \\
(\mathrm{pg})\end{array}$ \\
\hline A & 1 & 28 & $28 \mu \mathrm{g}$ & 280 & 28 & 2.8 & 0.28 & 28 \\
B & 1 & 28 & $2.8 \mathrm{mg}$ & 280 & 28 & 2.8 & 280 & \\
\hline
\end{tabular}

Table 4 Dilution nerve agents

\begin{tabular}{lllllllll}
\hline Agent & Step 0 $(\mu \mathrm{l})$ & Step 1 $(\mathrm{mg})$ & Step 2 & Step 3 & Step 4 & Step 5 & Step 6 (ng) & Step 7 \\
\hline Nerve agents & & & & & & & & \\
GA & 1 & 28 & $28 \mu \mathrm{g}$ & $280 \mathrm{ng}$ & $28 \mathrm{ng}$ & $2.8 \mathrm{ng}$ & 0.28 \\
GB & 1 & 28 & $28 \mu \mathrm{g}$ & $280 \mathrm{ng}$ & $28 \mathrm{ng}$ & $2.8 \mathrm{ng}$ & 0.28 \\
GD & 1 & 28 & $28 \mu \mathrm{g}$ & $280 \mathrm{ng}$ & $28 \mathrm{ng}$ & $2.8 \mathrm{ng}$ & 0.28 \\
GF & 1 & 28 & $28 \mu \mathrm{g}$ & $280 \mathrm{ng}$ & $28 \mathrm{ng}$ & & & \\
VX & 1 & 28 & $2.8 \mathrm{mg}$ & $280 \mu \mathrm{g}$ & $28 \mu \mathrm{g}$ & $2.8 \mu \mathrm{g}$ & 280 \\
\hline
\end{tabular}

The decision on which solvent to use for our analytical trials was solely based on the initial results obtained. At times, we changed solvents to obtain better results.

\subsection{Dilution series}

The test samples were diluted, according to the requirements given to the laboratory staff.

The first sample always represented $1 \mu l$ of the neat agent. The subsequent amounts were calculated based upon the surface area of the petri dish, namely $28 \mathrm{~cm}^{2}$.

The overview of the dilution steps is shown in Table 3. Series A was applied for 8 out of 9 agents. Series B had to be applied for the agent with the lowest vapour pressure-VX.

The levels of contamination are always (NATO) given in amounts per $\mathrm{cm}^{2}$. It was therefore extremely important for us to be able to calculate the results on that surface area.

The dilution was carried out by laboratory staff. They prepared the petri dishes and their content based on the values given to them.

\subsection{Trials nerve agents}

Step 0 was performed with pure (undiluted) CWA. All the figures below, titled "Agent type net", are referring to this step (Table 4).

Diluted CWA was used for the subsequent trials, for agents GA, GB, GD, and GF from step 1 to step 2, with a dilution factor of $10^{3}$. From step 2 to step 3 the factor was $10^{2}$, from 3 to $410^{1}$, from 4 to 5 again $10^{1}$, and the same applied to steps 5-6.

The last dilution step always represents the LOD, Limit of Detection. This is further explained in chapter 6 .

VX had to be dealt with differently, due to its relatively low vapour pressure compared to all other agents. It was always diluted by a factor of $10^{1}$. 
Table 5 Dilution blister agents

\begin{tabular}{lllllllll}
\hline Agent & $\begin{array}{l}\text { Step 0 } \\
(\mu \mathrm{l})\end{array}$ & $\begin{array}{l}\text { Step 1 } \\
(\mathrm{mg})\end{array}$ & $\begin{array}{l}\text { Step 2 } \\
(\mu \mathrm{g})\end{array}$ & Step 3 & $\begin{array}{l}\text { Step 4 } \\
(\mathrm{ng})\end{array}$ & $\begin{array}{l}\text { Step 5 } \\
(\mathrm{ng})\end{array}$ & $\begin{array}{l}\text { Step 6 } \\
(\mathrm{ng})\end{array}$ & $\begin{array}{l}\text { Step 7 } \\
(\mathrm{pg})\end{array}$ \\
\hline $\begin{array}{l}\text { Blister } \\
\text { agents }\end{array}$ & & & & & & & & \\
HD & 1 & 28 & 28 & $280 \mathrm{ng}$ & 28 & 2.8 & 0.28 & 28 \\
HN1 & 1 & 28 & 28 & $280 \mathrm{ng}$ & 28 & & & \\
HN3 & 1 & 28 & 28 & $280 \mathrm{ng}$ & 28 & 2.8 & 0.28 & \\
L1 & 1 & 28 & 28 & $2.8 \mu \mathrm{g}$ & & & & \\
\hline
\end{tabular}

\subsection{Trials blister agents}

Step 0 was performed with pure (undiluted) CWA. All the figures below, titled "Agent type net", refer to this step (Table 5).

Diluted CWA was used for the subsequent trials, for the agents HD, HN1 and HN3 from step 1 to step 2 with a dilution factor of $10^{3}$, from step 2 to step 3 the factor was $10^{2}$ and from 3 to $710^{1}$, respectively.

This series was somewhat different for Lewisite, as the dilution factor was $10^{3}$ from Step 1 to 2 , and only $10^{1}$ from 2 to 3 .

The last dilution step always represents the LOD, Limit of Detection. This is further explained in chapter 6 .

\section{Evaluation of field trials}

This chapter describes and evaluates the test results, based on:

- detectable concentration in the air and

- detectable concentration on a surface.

It also compares the test results to existing standards.

\subsection{Detectable concentration in air}

The concentration values were calculated based on the results of the laboratory trials. The instrument gives concentration values, based on calculations expressed in parts per trillion (volume). In order to compare said values to existing CWA health and safety standards, I transformed the pptv values into $\mathrm{ng} / \mathrm{m}^{3}$, by using the following simplified formula:

$$
\mathrm{mg} / \mathrm{mg}^{3}=\mathrm{ppm} \times \frac{\mathrm{MW}}{22.41}
$$

whereas MW stands for molecular weight; 22,41 is a conversion constant.

Detailed results are shown in Tables 6, 7, 8, 9, 10 and Figs. 1 and 2.

\subsubsection{Nerve agents}

Limit of detection (LOD): concentration in air The results are summarized in the table below. 
Table 6 LOD air nerve agents

\begin{tabular}{llllll}
\hline CWA & Name & $\begin{array}{l}\text { Reagent } \\
\text { ion }\end{array}$ & $\begin{array}{l}\text { LoD } \\
\text { (pptv) } \\
\text { for 1 s }\end{array}$ & $\begin{array}{l}\text { Molecular } \\
\text { weight } \\
\text { g/mol }\end{array}$ & $\begin{array}{l}\text { LoD in } \\
\mathrm{ng} / \mathrm{m}^{3}\end{array}$ \\
\hline GD & Soman & $\mathrm{NH}_{4}{ }^{+}$ & $\sim 20$ & 182.17 & $\sim 162$ \\
GF & Cyclosarin & $\mathrm{NH}_{4}{ }^{+}$ & $\sim 10$ & 180.157 & $\sim 80$ \\
GB & Sarin & $\mathrm{NH}_{4}{ }^{+}$ & $\sim 10$ & 140.09 & $\sim 125$ \\
GA & Tabun & $\mathrm{NH}_{4}{ }^{+}$ & $\sim 10$ & 162.13 & $\sim 117$ \\
VX & VX & $\mathrm{NH}_{4}{ }^{+}$ & $\sim 20$ & 267.37 & $\sim 238$ \\
\hline
\end{tabular}

Table 7 LOD air blister agents

\begin{tabular}{llllll}
\hline CWA & Name & Reagent ion & LoD (pptv) for 1 s & $\begin{array}{l}\text { Molecular weight } \\
\text { g/mol }\end{array}$ & LoD in ng/m ${ }^{3}$ \\
\hline $\mathrm{HD}$ & Sulfur mustard & $\mathrm{H}_{3} \mathrm{O}^{+}$ & $\sim 30$ & 159.08 & $\sim 212$ \\
$\mathrm{HN} 3$ & Nitrogen mustard & $\mathrm{NH}_{4}{ }^{+}$ & $\sim 20$ & 204.52 & $\sim 182$ \\
$\mathrm{HN} 1$ & Nitrogen mustard & $\mathrm{NH}_{4}{ }^{+}$ & $\sim 20$ & 170.08 & $\sim 125$ \\
$\mathrm{~L}$ & Lewisite & $\mathrm{H}_{3} \mathrm{O}^{+}$ & $\sim 20$ & 207.32 & $\sim 152$ \\
\hline
\end{tabular}

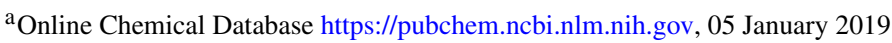

Table 8 NATO safe residual contamination levels (NATO Standard NATO STANREC 5784 Edition November 2015)

Table 9 LOD surface nerve agents

\begin{tabular}{llll}
\hline Purpose/task & Agent & Essential g/m $\mathrm{m}^{2}$ & Desirable $\mathrm{g} / \mathrm{m}^{2}$ \\
\hline Reconnaissance & CWA & 0.1 & As for personnel \\
Materiel & G & 0.1 & As for personnel \\
& V & 0.02 & \\
Personnel & H & 0.1 & \\
& GA, GB & 0.0528 & 0.0528 \\
& GD & 0.0111 & 0.0111 \\
& GF & 0.0106 & 0.0106 \\
& VX & 0.0003 & 0.0003 \\
& HD & 0.0150 & 0.0150 \\
\hline
\end{tabular}

\begin{tabular}{lllll}
\hline CWA & Name & Reagent ion & ng/cm & NATO levels ng/cm \\
\hline GD & Soman & $\mathrm{NH}_{4}{ }^{+}$ & 0.28 & 1110 desirable \\
GF & Cyclosarin & $\mathrm{NH}_{4}{ }^{+}$ & 28 & 106 desirable \\
GB & Sarin & $\mathrm{NH}_{4}{ }^{+}$ & 0.28 & 5280 desirable \\
GA & Tabun & $\mathrm{NH}_{4}{ }^{+}$ & 0.28 & 5280 desirable \\
VX & VX & $\mathrm{NH}_{4}{ }^{+}$ & 280 & 2000 essential \\
\hline
\end{tabular}


Table 10 LOD surface blister agents

\begin{tabular}{|c|c|c|c|c|}
\hline CWA & Name & Reagent ion & $\mathrm{ng} / \mathrm{cm}^{2}$ & $\begin{array}{l}\text { NATO levels } \\
\mathrm{ng} / \mathrm{cm}^{2}\end{array}$ \\
\hline $\mathrm{HD}$ & Sulfur mustard & $\mathrm{H}_{3} \mathrm{O}^{+}$ & 0.028 & 1500 desirable \\
\hline HN3 & $\begin{array}{l}\text { Nitrogen } \\
\text { mustard }\end{array}$ & $\mathrm{NH}_{4}{ }^{+}$ & 0.28 & 1500 desirable \\
\hline HN1 & $\begin{array}{l}\text { Nitrogen } \\
\text { mustard }\end{array}$ & $\mathrm{NH}_{4}{ }^{+}$ & 28 & 1500 desirable \\
\hline L1 & Lewisite & $\mathrm{H}_{3} \mathrm{O}^{+}$ & 2800 & 10,000 essential \\
\hline
\end{tabular}

\section{HD Sulfur Mustard}

Reagent Ion $\mathrm{H}_{3} \mathrm{O}^{+}$

LOD (pptv) for 1s: $\sim 30$

The two colors (orange and blue) represent the two different masses.

The limit of detection is the standard deviation of the signal (noise), multiplied by 3 ( $3 *$ noise).

The time in second corresponds to the total time of $\mathrm{HD}$ measurements, including all dilutions.

The blue line refers to the mass of 123,03 , which is the mass of $\mathrm{HD}$ minus the mass of $\mathrm{HCl}$.

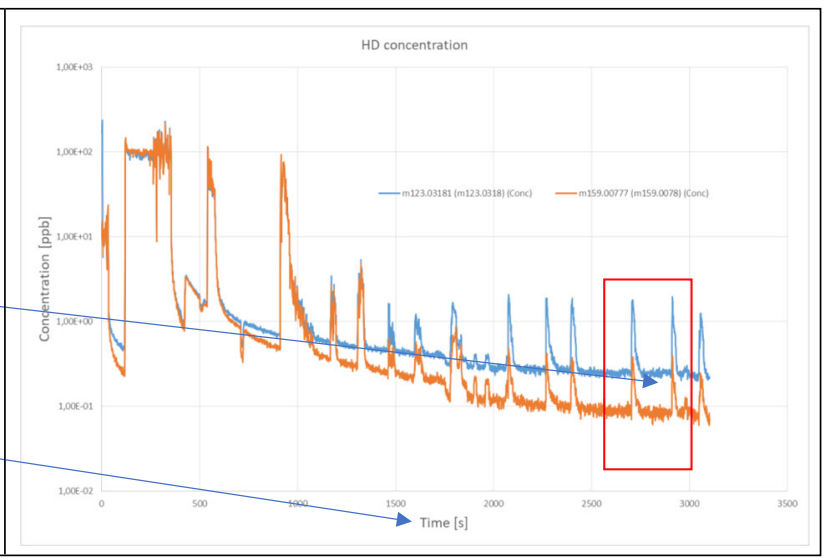

Fig. 1 HD LOD air

\begin{tabular}{|c|}
\hline HD \\
\hline Step 1: $28 \mathrm{mg}$ \\
\hline Step 2: $28 \mu \mathrm{g}$ \\
\hline Step 3: 280ng \\
\hline Step 4: 28ng \\
\hline Step 5: $2,8 \mathrm{ng}$ \\
\hline Step 6: $0,28 \mathrm{ng}$ \\
\hline Step 7: 28pg \\
\hline $\begin{array}{l}\text { Step } 7 \text { represents the LOD for } \\
\text { surface } \\
28 \mathrm{pg} / \mathrm{cm}^{2}\end{array}$ \\
\hline
\end{tabular}

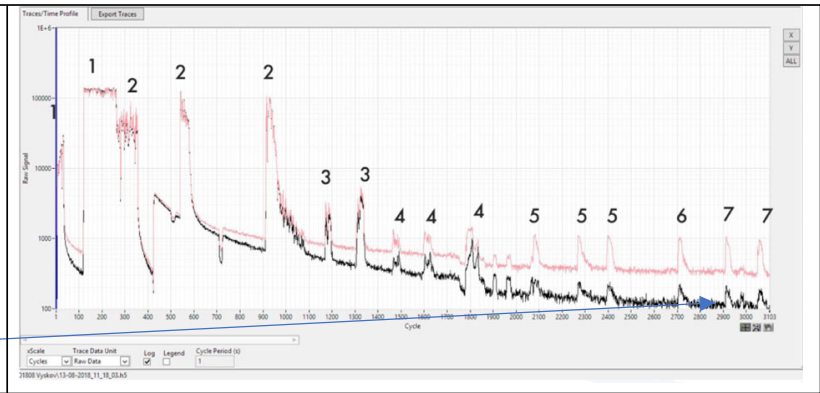

Fig. 2 LOD surface HD

\subsubsection{Blister agents}

Limit of detection ( $L O D)$ : concentration in air It has to be noted that the concentration values below refer to the volume of the funnel $\left(30 \mathrm{~cm}^{3}\right)$, measured at a distance of $10 \mathrm{~cm}$ from the surface of the petri dish.

The results are summarized in the table below. 


\subsection{Detectable concentration on surface}

The LoD on surface areas has been identified through our field trials. The results are described hereunder.

NATO defines its essential and desirable levels of residual and safe surface contamination as follows:

The results of the field trials have shown that the detection and identification levels of the PTR-ToF-MS technology lie well within these desirable NATO limits, apart from VX and $\mathrm{L}$, for which the instrument meets the essential limit.

\subsubsection{Nerve agents}

Limit of detection: concentration on surface The values in the table below represent the area where the noise (background) signal could still be clearly distinguished from the background. At the subsequent step of dilution, this was no longer possible.

\subsubsection{Blister agents}

Limit of detection ( $L O D)$ : concentration on surface The values in the table below represent the area where the obtained signal could still be distinguished from the background (noise). At the subsequent step of dilution, this was no longer possible.

\section{Conclusions: clearance decontamination supported by PTR-ToF-MS-a way forward?}

Multiple decontamination cycles might be required to render contaminated surfaces safe to a level that they do not pose any threat to humans anymore, which means that such levels do not cause any noticeable health effect. How do the relevant authorities perform checks on potentially high residual contamination levels? For the moment being, this process is time-consuming and involves elaborate analytical procedures and laboratories. The IONICON PTR-ToF-MS technology can be used on site and can produce realtime-immediate - results. It does not require taking any samples, is easy to use, and analytically reliable. Field trials have clearly shown that NATO essential and desirable detection levels can be reached. In my view, the Proton Transfer Reaction-Time of Flight-Mass Spectrometry trace detection technology is an invaluable asset supporting civilian authorities in determining safe levels of surface contamination in real time, during decontamination cycles, and after the completion of decontamination operations.

Data Availability Statement This manuscript has associated data in a data repository. [Authors' comment: The raw data were generated at a specialized facility, allowing access to chemical warfare agents. The derived data supporting the findings of this article are available from the corresponding author on request].

Funding Open access funding provided by Università degli Studi di Roma Tor Vergata within the CRUICARE Agreement. This research was not publicly funded. 


\section{Declarations}

Conflict of interest The authors declare that they have no conflict of interest.

Open Access This article is licensed under a Creative Commons Attribution 4.0 International License, which permits use, sharing, adaptation, distribution and reproduction in any medium or format, as long as you give appropriate credit to the original author(s) and the source, provide a link to the Creative Commons licence, and indicate if changes were made. The images or other third party material in this article are included in the article's Creative Commons licence, unless indicated otherwise in a credit line to the material. If material is not included in the article's Creative Commons licence and your intended use is not permitted by statutory regulation or exceeds the permitted use, you will need to obtain permission directly from the copyright holder. To view a copy of this licence, visit http://creativecommons.org/licenses/by/4.0/.

\section{References}

1. Website. https://www.opcw.org/our-work/what-chemical-weapon. Accessed 25 Nov 2018

2. Online Article. https://www.ncbi.nlm.nih.gov/pmc/articles/PMC3148621/. Accessed 25 Nov 2018

3. NATO Standard NATO AEP-58 Volume I Combined Operational Characteristics, Technical Specifications, Test Procedures and Evaluation Criteria for Chemical, Biological, Radiological and Nuclear Decontamination Equipment Edition B, Version 1 October 2013, Annex C-2

4. Online Encyclopedia. https://www.britannica.com/science/trace-element. Accessed 01 Dec 2018

5. Book McNaught A.D., Wilkinson A., Compendium of Chemical Terminology: The Gold Book, second ed., Blackwell Science, London, UK (1997)

6. NATO Standard NATO STANREC 4784 CBRN Clearance Decontamination, Study Draft 1, November 2015

7. Annex 1: International Master's Course in Protection Against CBRNe Events—2nd Level VIII Cycle Final Dissertation Dieter Rothbacher, pp. 67-76 